\title{
Study on Supporting Protection of Tunnel Opening near a Rock Layer under Elastic Deformation of Surrounding Rock
}

\author{
Zhigang Jia $(\mathbb{D})$ and Yongsong $\mathrm{Li}$ \\ School of Architecture Engineering, Huanghuai University, Zhumadian, China \\ Correspondence should be addressed to Zhigang Jia; jiazhigang@huanghuai.edu.cn and Yongsong Li; liys@huanghuai.edu.cn
}

Received 25 June 2021; Accepted 30 August 2021; Published 16 September 2021

Academic Editor: Haojie Lian

Copyright (c) 2021 Zhigang Jia and Yongsong Li. This is an open access article distributed under the Creative Commons Attribution License, which permits unrestricted use, distribution, and reproduction in any medium, provided the original work is properly cited.

\begin{abstract}
Due to the limitation of geological conditions and route alignment, tunnel engineering will inevitably pass through special sections such as shallow buried section, broken rock layer, and loss and weak rock stratum. Tunnel construction in these special sections will easily lead to tunnel collapse, landslide of portal slope, excessive deformation of supporting structure, and even deformation and damage accidents, which are high-incidence areas of engineering safety accidents. In this paper, a $3 \mathrm{D}$ numerical model is established based on a practical engineering to analyze the deformation and stress variation of surrounding rock of the tunnel with the in-advance support technology. According to the monitoring results of the actual project, the deformation law of the soft rock section at the tunnel entrance is mastered. The deformation of surrounding rock of the tunnel under the support condition of changing the three main parameters, such as ring spacing, pipe diameter, and pipe length, is analyzed, and the effect of controlling the deformation of surrounding rock with different parameters is studied. The deformation, stress characteristics, and plastic zone distribution of surrounding rock by a single side wall guide method and ring excavation and retaining core soil method in advance support are numerically simulated and studied.
\end{abstract}

\section{Introduction}

When the tunnel passes through the mountain, it will be inclined to cross with the mountain with an asymmetrical terrain and inclined angle, resulting in asymmetrical load of rock mass on the tunnel. In this case, it is a biased tunnel. The tunnel is very prone to collapse due to the uneven stress of surrounding rock [1-3]. Therefore, in the tunnel construction in these sections with poor geological conditions, in order to ensure the smooth completion of the project, in-advance support technologies such as shed pipe, small duct, and the horizontal rotary jet grouting piles should be adopted to control the deformation of surrounding rock [4]. In order to improve the support effect, different advanced support technologies are often used together.

(1) The construction of a tunnel opening section is the beginning of the tunnel engineering and the key section connecting the tunnel body. The successful completion of the tunneling project has a great impact on the progress and cost of the later project and is closely related to the safety of the whole tunnel. It is very necessary for each mountain tunnel to ensure that the deformation of surrounding rock is controlled within the allowable range during construction. Therefore, it is of great value to study the deformation control of surrounding rock at the entrance [5-7]

(2) At present, the supporting measures of the tunnel portal section have been very comprehensive, among which the advanced support is necessary for each tunnel with poor geological conditions. However, the terrain, geological conditions, surrounding rock characteristics, and design parameters of each tunnel portal section are different. The deformation of surrounding rock under the advanced support is not the same, and the support effect is also different. 
Therefore, the design plan of advanced support is not universal for each tunnel. Selecting the most suitable advanced support plan and excavation method can improve the construction quality and production efficiency of the tunnel engineering, ensure the construction safety, save the construction period, reduce the cost, and increase the production capacity. Therefore, it is of great construction promotion value to compare and select plans [8].

In this paper, based on a coal mine tunnel under construction as the background, the tunnel exit portal section buried depth is shallow, geological conditions are not ideal, the field construction process found that the tunnel portal section of multiple surrounding rock settlement is too large, and deformation is large, prone to collapse and roof fall accidents [9-12]. The buried depth of this section is $3.5 \mathrm{~m}$ to $16 \mathrm{~m}$, and the slope is $31.3 \%$. The measured spacing for the exit is $16.1 \mathrm{~m}$, and the general spacing for the hole body is $25-35 \mathrm{~m}$. Compared with other positions of the tunnel, the shallow hole section of the tunnel is more vulnerable to weathering, which will reduce the mechanical parameters of surrounding rock and make it difficult for the shallow hole to form arch effect, further affecting the stability of the shallow hole. When the new Austrian tunneling method is adopted, the shallow buried hole section of the tunnel can effectively alleviate the complicated geological conditions, rock fragmentation, and serious weathering of the tunnel opening by adopting the way of advance support. Therefore, the advance support is of great significance to the reinforcement of shallow buried tunnel openings.

\section{Theoretical Analysis and Supporting Principles of the Short-Range Coal Seam Roadway}

\subsection{Supporting Theory of the Short-Range Coal Seam Roadway}

(1) The core content of the suspension theory is as follows: if there is a weak rock layer on the roof of the roadway, the weak rock layer needs to be connected with the stable rock layer at the bottom, and the anchor acts as a suspension [12]. When the roof of the roadway is a hard rock layer and a soft broken rock layer, respectively, the effect diagram of suspension action is shown in Figure 1, respectively

(2) Composite beam theory

The theory is analyzed in view of multiple layers of the roadway roof. At this time, the application of bolt support can, on the one hand, increase the friction between layers and effectively prevent the occurrence of sliding and separation in each layer. On the other hand, the shear strength of the rock layer is increased, and the thin layers are fixed to each other, equivalent to a thick coal seam. The theoretical effect diagram is shown in Figure 2.

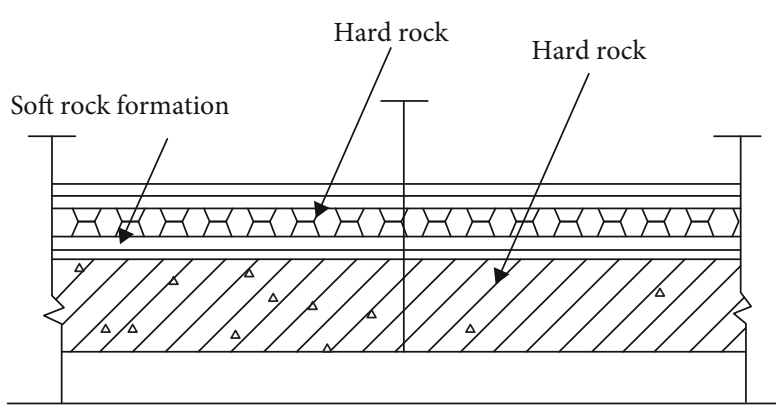

Naturally balanced arch weak rock formation

Figure 1: Suspension action of bolt support.

(3) Combination arch theory

In this theory, in order to prevent the continuous expansion of the crushing area of surrounding rock, a prestressed bolt is installed to achieve the supporting effect. A pressure stress zone with conical distribution will be formed from both ends of the supporting bolt to the center of the bolt. Moreover, when the bolt spacing is small, a uniform composite compression arch will be formed to increase the strength of surrounding rock, which is commonly used in circular or arch tunnels.

2.2. Support Optimization of Surrounding Rock of the Near Coal Seam Mining Roadway. Taking the coal mine as an example, the main coal seams are no. 4 and no. 5 coal. Among them, the average thickness of no. 4 coal seam is $4.2 \mathrm{~m}$, most of which can be mined; the average thickness of no. 5 coal seam is $4.5 \mathrm{~m}$, all of which can be mined. The average interval between the two coal seams is $6.0 \mathrm{~m}$, which belongs to the typical close distance coal seam. The downward mining method is adopted; that is, the no. 4 coal seam is first mined, the roadway section is $4.2 \times 4.7 \mathrm{~m}$, and the $20 \mathrm{~m}$ protective coal pillar is reserved, and then, the no. 5 coal seam is mined. After the no. 4 coal seam is mined out, the no. 5 coal working face's transportation gateway is arranged under the no. 4 coal goaf and $8.3 \mathrm{~m}$ away from the protection coal pillar of the no. 4 coal section. The roadway section is $4.5 \times 4.7 \mathrm{~m}$, and the combined symmetrical support plan of "bolt (cable)+metal mesh" is adopted. Due to the neglect of the asymmetry of the stress and deformation of the roadway side, although the no. 5 coal seam transport gateway is arranged in the stress-reducing area, there are still serious side heave and roof subsidence deformation, the convergence rate of the two sides is as high as $40 \sim 45 \mathrm{~mm} / \mathrm{d}$, the roadway side still has serious asymmetric deformation, and the side bolt (cable) turns over in different degrees, which seriously affects the normal mining of the no. 5 coal seam. In this section, the limit equilibrium zone width, fracture zone width, and safe staggered distance of upper and lower coal seams will be determined according to the above theoretical equation, and the bolt support design plan will be optimized. The original support plan of the upper and lower coal seam roadway is shown in Figure 3. 


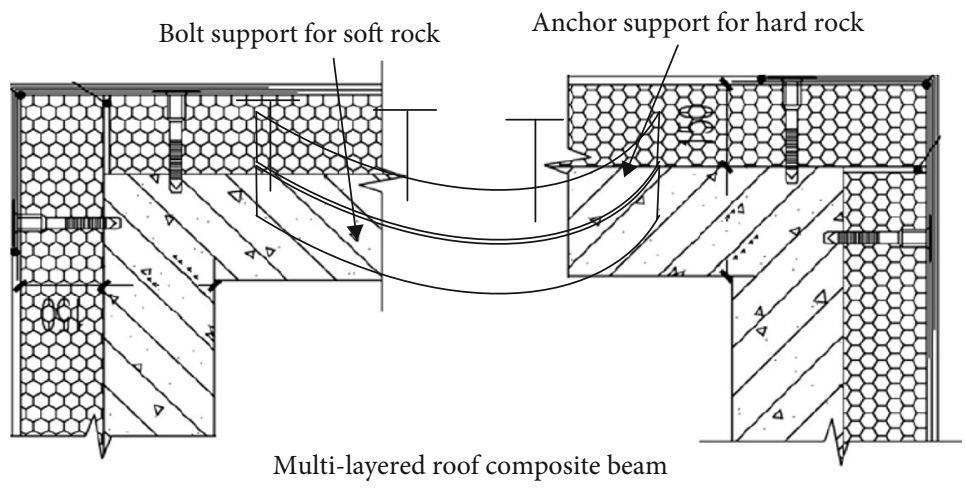

Figure 2: Composite beams with a multilayered roof.
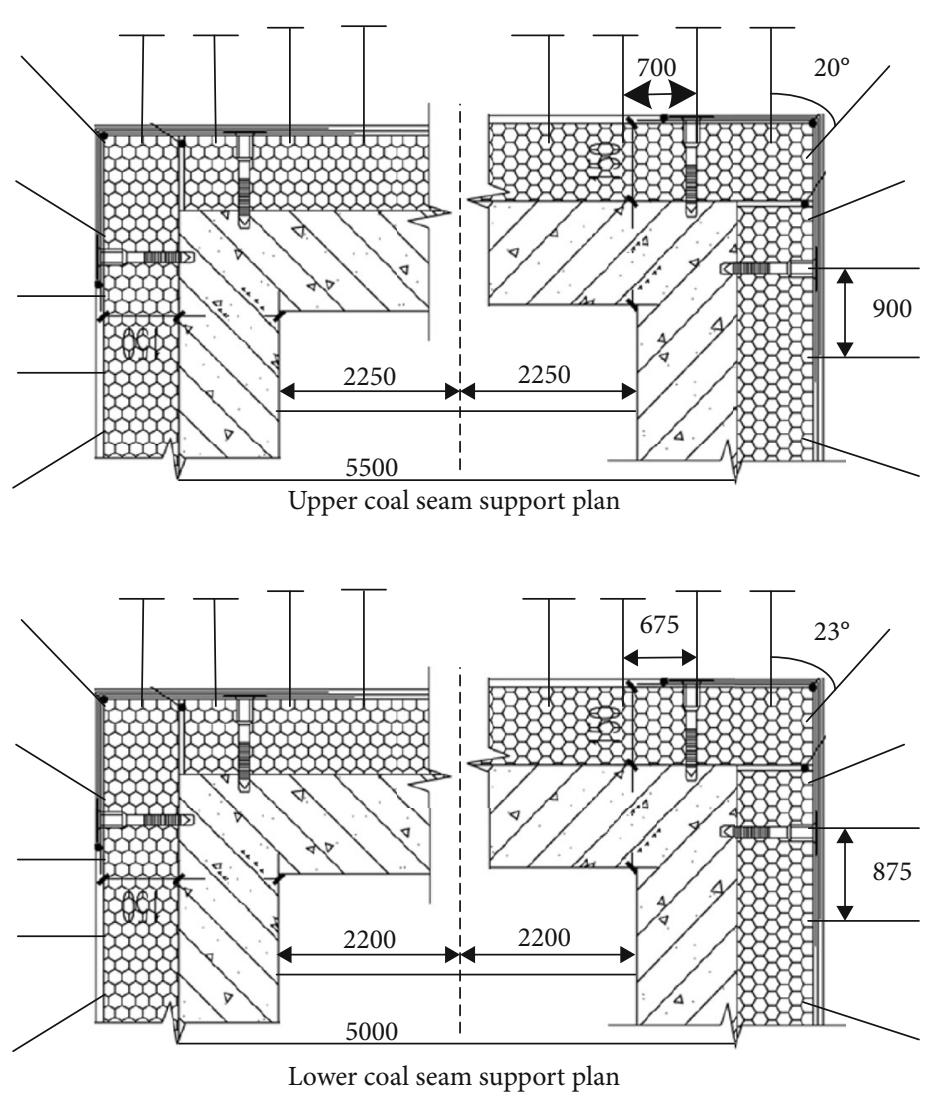

FIGURE 3: Original supporting plan of the face transportation channel.

\subsubsection{Original Supporting Plan of the Roadway in the Upper} Coal Seam

(1) Roadway Roof Support. The roof bolt adopts a $\Phi 18 \times$ $2200 \mathrm{~mm}$ left screw rigid resin bolt, with 4 bolts in each row, and the spacing between rows is $1400 \times 1000 \mathrm{~mm}$. The bolt adopts two z2360 medium resin anchoring agents, adopts a high-strength arch tray with the specification of $150 \times 150 \times 8 \mathrm{~mm}$, and is equipped with a high-strength spherical washer. The installation angle of the bolt at both ends near the roof is offset by $20^{\circ}$ to the inner side of the roadway; the roof anchor cable adopts $\Phi 18 \times 7000 \mathrm{~mm}$ high-strength prestressing. There are 3 anchor cables in total, which are symmetrically arranged along the center line of the roadway, with a spacing of $1400 \times 2100 \mathrm{~mm}$, and three $\mathrm{Z} 2360$ medium resin anchoring agents are used; the metal mesh is a square metal mesh woven with a $10 \#$ iron wire, with a mesh size of $100 \times 100 \mathrm{~mm}$, which shall be cut reasonably according to the size of the roadway roof, and the metal mesh shall be flattened and tightened during laying.

(2) Parameters of the Sidewall Bolt. A sidewall bolt adopts a $\Phi 18 \times 2200 \mathrm{~mm}$ left screw rigid resin anchor rod, with 5 
bolts in each row, with row spacing of $900 \times 900 \mathrm{~mm}$. The bolt adopts two branches of the Z2360 medium resin anchoring agent, adopts a high-strength arch tray with specification of $150 \times 150 \times 8 \mathrm{~mm}$, and is equipped with a highstrength spherical washer. The installation angle of the anchor rod near the top plate and bottom plate end is, respectively, $20^{\circ}$ to the top plate and bottom plate; the metal mesh is woven with a $10 \#$ iron wire square metal mesh with a mesh size of $50 \times 50 \mathrm{~mm}$ which shall be cut reasonably according to the size of roadway side, and the metal mesh shall be flattened and tightened during laying [12].

\subsubsection{Original Supporting Plan of the Lower Coal Seam Roadway}

(1) Roadway Roof Support. The roof bolt adopts a $\Phi 18 \times$ $2200 \mathrm{~mm}$ left screw rigid resin bolt, with 4 bolts in each row, and the spacing between rows is $1400 \times 1000 \mathrm{~mm}$. The bolt adopts two Z2360 medium resin anchoring agents, adopts a high-strength arch tray with the specification of $150 \times 150 \times 8 \mathrm{~mm}$, and is equipped with a high-strength spherical washer. The installation angle of the bolt at both ends near the roof is offset by $23^{\circ}$ to the inner side of the roadway; the roof anchor cable adopts $\Phi 18 \times 5500 \mathrm{~mm}$ high-strength prestressing. There are 3 anchor cables in total, which are symmetrically arranged along the center line of the roadway, with a spacing of $1400 \times 2100 \mathrm{~mm}$, and three Z2360 medium resin anchoring agents are used; the metal mesh is a square metal mesh woven with a 10\# iron wire, with a mesh size of $100 \times 100 \mathrm{~mm}$, which shall be cut reasonably according to the size of the roadway roof, and the metal mesh shall be flattened and tightened during laying [13].

(2) Parameters of the Sidewall Bolt. The sidewall bolt adopts a $\Phi 18 \times 2200 \mathrm{~mm}$ left screw rigid resin bolt, with 5 bolts in each row and $875 \times 875 \mathrm{~mm}$ spacing between rows. The bolt adopts two Z2360 medium resin anchoring agents, adopts a high-strength arch tray with specification of $150 \times 150 \times 8$ $\mathrm{mm}$, and is equipped with a high-strength spherical washer. The installation angle of the bolt near the end of the top plate and bottom plate is, respectively, $23^{\circ}$ to the direction of the roof and bottom plate; the metal mesh is made of a $10 \#$ iron wire The mesh size of a square metal mesh is 50 $\times 50 \mathrm{~mm}$, which is cut reasonably according to the size of the roadway side, and the metal mesh shall be flattened and tightened during laying [14].

\subsection{Optimization Calculation of Bolt Support Parameters}

(1) When the bolt length supports the surrounding rock of the roadway, the length of all anchors in the supporting structure of the roadway is the same and no less than $L_{0}$ [15]. In combination with the actual engineering situation, it is found that the support effect of the roof of the mining roadway is realized through the formation of "combined arch of anchoring layer" by anchor rods, so the "combined arch theory" is adopted for analysis and calculation [16].
Therefore, the roof length can be calculated by the following equation:

$$
L_{p} \geq L_{1}+L_{2}+L_{3}
$$

In equation (1), $L_{1}$ is the exposed length of the bolt, $L_{1}$ $=$ the thickness of backing plate + the thickness of nut +( $0.02 \sim 0.03) \mathrm{m}$, and $L_{1}=0.10 \mathrm{~m} ; L_{2}$ is the effective length of the bolt; and $L_{3}$ is the anchorage length of the bolt and $L_{3}$ $=0.3 \sim 0.4 \mathrm{~m}$.

Calculation of effective length $L_{2}$ of the roof bolt

(i) Roof bolt for the upper seam

In combination with the geological data of the roadway, the values of relevant parameters are determined as follows: $a=2.30 \mathrm{~m}$ and width $L_{s}=2.42 \mathrm{~m}$ of the side fracture zone, and the value of the Platt coefficient is 2.5 , so that

$$
\begin{aligned}
& a_{1}=2.3+2.42=4.72 \\
& L_{2}^{\prime}=\frac{4.72}{2.5}=1.89 \mathrm{~m} .
\end{aligned}
$$

\section{(ii) Lower seam roof bolt}

In combination with the geological data of the roadway, the relevant parameters are determined as follows: half width $a=2.30 \mathrm{~m}$ and width $L_{s}^{\prime}=2.93 \mathrm{~m}$ of the fracture zone at the side, and the value of the Platt coefficient is 2.7 , so that

$$
\begin{aligned}
& a_{1}=2.3+2.93=5.23 \mathrm{~m}, \\
& L_{2}^{\prime}=\frac{5.23}{2.7}=1.94 \mathrm{~m}
\end{aligned}
$$

The roof length of the upper coal seam is calculated as follows: $L_{n} \geq 2.29 \sim 2.39 \mathrm{~m}$. In combination with the actual situation and engineering analogy, the length of the anchor rod is $2.4 \mathrm{~m}$. The roof length of the lower coal seam is obtained as follows: $L_{0}^{\prime} \geq 2.34 \sim 2.44 \mathrm{~m}$. By combining the actual situation and engineering analogy, the bolt length is $2.4 \mathrm{~m}[17]$.

(2) Calculation of effective length $L_{2}$ of the floor anchor rod

According to the results of mining roadway floor analysis and considered according to the most unfavorable combination, the effective length of roadway roof rock when it reaches the failure depth is the effective length of the roadway roof bolt, that is, the effective length of the roof bolt in the upper coal seam floor $L_{2}=3.0 \mathrm{~m}$ and the effective length of the roof bolt in the lower coal seam floor $L_{2}=3.39 \mathrm{~m} \mathrm{[18]}$.

The length of the upper coal seam floor is calculated as follows: $L_{0} \geq 3.40 \sim 3.50 \mathrm{~m}$. In combination with the actual situation on the site and engineering analogy, the length of 
the anchor rod is $3.4 \mathrm{~m}$. The roof length of the lower coal seam is obtained as follows: $L_{0}^{\prime} \geq 3.79 \sim 3.89 \mathrm{~m}$. In combination with the actual situation and engineering analogy, the length of the anchor rod is $3.8 \mathrm{~m}$ [19].

(3) Calculation of effective length $L_{2}$ of the sidewall bolt

(i) Upper seam sidewall bolt

The width of the coal sidewall crushing zone of the coal seam is $L_{s}=2.42 \mathrm{~m}$; then, the effective length of the bolt $L_{2}$ is

$$
L_{2} \geq L_{r}=2.42 \mathrm{~m}
$$

(ii) Lower seam sidewall bolt

The width of the coal sidewall crushing zone of the coal seam is $L_{s}=2.93 \mathrm{~m}$; then, the effective length of the bolt $L_{2}$ is

$$
L_{2} \geq L_{s}=2.93 \mathrm{~m}
$$

The roof length of the upper coal seam is calculated as follows: $L_{0} \geq 2.82 \sim 2.92 \mathrm{~m}$. In combination with the actual situation and engineering analogy, the length of the anchor rod is $2.9 \mathrm{~m}$. The roof length of the lower coal seam is obtained as follows: $L_{0}^{\prime} \geq 3.33 \sim 3.43 \mathrm{~m}$. In combination with the actual situation and engineering analogy, the bolt length is $3.4 \mathrm{~m}$.

(4) For the use of bolt support in stoping the roadway, it is generally considered to take equal bolt spacing in construction technology to deal with; then, the bolt spacing $a$ can be calculated according to the following equation:

$$
a \leq 0.5 L_{0} .
$$

(i) Upper coal seam spacing roof bolt spacing from equation (8):

$$
a \leq 0.5 \times 2.4=1.2 \mathrm{~m}
$$

In combination with the engineering practice and construction experience, considering the roadway cross section size, the row spacing between the roof and anchor is 1200 $\times 1200 \mathrm{~mm}$.

(ii) The row spacing between floor bolts is shown in equation (8) as follows:

$$
a \leq 0.5 \times 3.4=1.7 \mathrm{~m} \text {. }
$$

In combination with the engineering practice and construction experience, considering the roadway section size, the row spacing between bottom anchors is $830 \times 830 \mathrm{~mm}$.

(iii) The row spacing of sidewall bolts is shown in equation (8) as follows:

$$
a \leq 0.5 \times 2.9=1.45 \mathrm{~m}
$$

In combination with the engineering practice and construction experience, considering the roadway cross section size, the row spacing between the sidewalls is $900 \times 900$ $\mathrm{mm}$.

(5) The row spacing of bolts in the lower coal seam

(i) The row spacing of roof bolts is shown in equation (8) as follows:

$$
a \leq 0.5 \times 2.4=1.2 \mathrm{~m} \text {. }
$$

In combination with the engineering practice and construction experience, considering the roadway cross section size, the row spacing between the roof and anchor is 1200 $\times 1200 \mathrm{~mm}$.

(ii) The row spacing between the bottom bolts is shown in equation (8) as follows:

$$
a \leq 0.5 \times 3.8=1.9 \mathrm{~m} \text {. }
$$

In combination with the engineering practice and construction experience, considering the roadway section size, the row spacing between bottom anchors is $850 \times 850 \mathrm{~mm}$.

(iii) The row spacing between the side bolts is shown in equation (9) as follows:

$$
a \leq 0.5 \times 3.4=1.7 \mathrm{~m} \text {. }
$$

In combination with the engineering practice and construction experience, considering the roadway cross section size, the row spacing between the sides is $1000 \times 1000 \mathrm{~mm}$.

(iv) The diameter of the anchor rod is determined by the relationship between the anchoring force and the tensile strength of the bolt body materials:

$$
Q \leq \frac{\pi d^{2} \sigma}{4}
$$

Then, the calculation equation of the bolt diameter shall 
meet the following equation:

$$
d \geq 1.13 \sqrt{\frac{Q}{\sigma_{t}}},
$$

where $d$ is the diameter of the anchor rod; $\sigma_{t}$ is the tensile strength of the bolt rod material, which is $360 \mathrm{MPa}$ according to the actual measurement; and $Q$ is the anchoring force of the anchor rod (not less than $70 \mathrm{kN}$ ), taking $90 \mathrm{kN}$.

Substituting the relevant data into equation (16) shows that

$$
d \geq 1.13 \sqrt{\frac{90 \times 10^{3}}{360 \times 10^{\prime}}}=17.9 \mathrm{~mm}
$$

In order to meet the requirement of support strength, the bolt diameter is $20 \mathrm{~mm}$.

\section{Optimization Design of the Bolt Support Plan}

\subsection{Support Plan after Optimization of the Upper Coal Seam Roadway}

3.1.1. Roadway Roof Support. The roof bolt adopts a left screw rigid resin bolt, 4 in each row, with $\Phi 20 \times 2400 \mathrm{~mm}$ spacing between rows. The roof bolt adopts 2 Z2360-type resin anchorage agents, adopts a high-strength arch tray, with the specification of $1200 \times 1200 \mathrm{~mm}$, and is matched with a high-strength spherical washer. The installation angle of the bolt near the two ends of the roof is offset by $20^{\circ}$ to the inside of the roadway. The roof anchor cable is made of a high-strength prestressed steel strand, with a total of three anchor cables arranged symmetrically along the center line of the roadway. The spacing between the cables is $\Phi 18 \times$ $7000 \mathrm{~mm}$. Three Z2360-type resin anchor agents are adopted. The metal mesh is a square metal mesh woven with a 10\# iron wire, and the mesh size is $100 \times 100 \mathrm{~mm}$. The mesh should be cut reasonably according to the size of the roadway roof, and the metal mesh should be paved and tensioned [20].

3.1.2. Roadway Floor Bolt Support. The floor bolt adopts a $\Phi 20 \times 3400 \mathrm{~mm}$ left screw rigid resin bolt, 5 pieces in each row, and the spacing between rows is $830 \times 830 \mathrm{~mm}$. The bolt adopts two Z2360 medium resin anchoring agent, adopts a high-strength arch tray with specification of 150 $\times 150 \times 8 \mathrm{~mm}$, and is equipped with a high-strength spherical washer; the metal mesh adopts a square metal mesh woven with a $10 \#$ iron wire, with mesh size of $100 \times 100$ $\mathrm{mm}$, which is cut reasonably according to the side size of the roadway, and the metal mesh shall be laid smooth and tightened [21].

3.1.3. Bolt Support of the Roadway Sidewall. The sidewall bolt is a $\Phi 20 \times 2900 \mathrm{~mm}$ left screw rigid resin bolt, 5 pieces in each row, and the spacing between rows is $900 \times 900$ $\mathrm{mm}$. The bolt adopts two Z2360 medium resin anchoring agents, adopts a high-strength arched tray with the specification of $150 \times 150 \times 8 \mathrm{~mm}$, and is equipped with a high-strength spherical washer. The installation angle of the bolt near the end of the roof and bottom plate is, respectively, $20^{\circ}$ to the direction of the roof and bottom plate; the metal mesh is a square metal mesh woven with a 10\# iron wire. The mesh size is $50 \times 50 \mathrm{~mm}$, which should be cut reasonably according to the size of the roadway side, and the metal mesh should be flattened and tightened during laying [22].

The optimized support plan of the upper coal seam roadway is shown in Figure 4.

\subsection{Support Plan after Optimization of the Lower Coal Seam Roadway}

3.2.1. Roadway Roof Support. The roof bolt adopts a $\Phi 20$ $\times 2400 \mathrm{~mm}$ left screw resin bolt with 4 bolts in each row and $1200 \times 1200 \mathrm{~mm}$ row spacing. The bolt adopts two Z2360-type resin anchorage agents, adopts a high-strength arch tray with $150 \times 150 \times 8 \mathrm{~mm}$ specification, and is matched with a high-strength spherical gasket. The installation angle of the bolt near the two ends of the roof is offset by $20^{\circ}$ to the inside of the tunnel. The roof anchor cable is made of a high-strength prestressed steel strand, with a total of three anchor cables arranged symmetrically along the center line of the roadway. The spacing between the cables is $1400 \times 2100$. Three Z2360-type resin anchor agents are adopted. The metal mesh is a square metal mesh woven with an iron wire 10\#, and the mesh size is $100 \times 100 \mathrm{~mm}$. The mesh is cut reasonably according to the size of the roadway roof, and the metal mesh should be paved and tensioned [23].

3.2.2. Roadway Floor Bolt Support. The bottom bolt adopts a $\Phi 20 \times 3800 \mathrm{~mm}$ left screw resin bolt with 5 bolts in each row and $850 \times 850 \mathrm{~mm}$ spacing between rows. The bolt adopts 2 Z2360 medium resin anchorage agents, adopts a high-strength arch tray with $150 \times 150 \times 8 \mathrm{~mm}$ specification, and is matched with a high-strength spherical washer. The metal mesh is a square metal mesh woven with an iron wire $10^{\#}$, and the mesh size is $100 \times 100$ $\mathrm{mm}$. The mesh should be cut reasonably according to the size of the roadway side, and the metal mesh should be paved and tensioned [24].

3.2.3. Roadway Sidewall Bolt Support. The left screw rigid resin bolt of $\Phi 20 \times 3400 \mathrm{~mm}$ is used for the sidewall bolt, with 5 bolts in each row and the spacing $1000 \times 1000 \mathrm{~mm}$ between rows. The bolt adopts two Z2360 medium resin anchoring agents, adopts a high-strength arched tray, and is equipped with a high-strength spherical washer. The installation angle of the bolt near the top plate and bottom plate end is, respectively, $20^{\circ}$ to the top plate and bottom plate; the metal mesh adopts a square metal mesh woven with a 10 \# iron wire, and the mesh is $50 \times 50 \mathrm{~mm}$ in size. It should be cut reasonably according to the size of the side of the roadway. When laying, the metal mesh should be flattened and tightened [25]. 


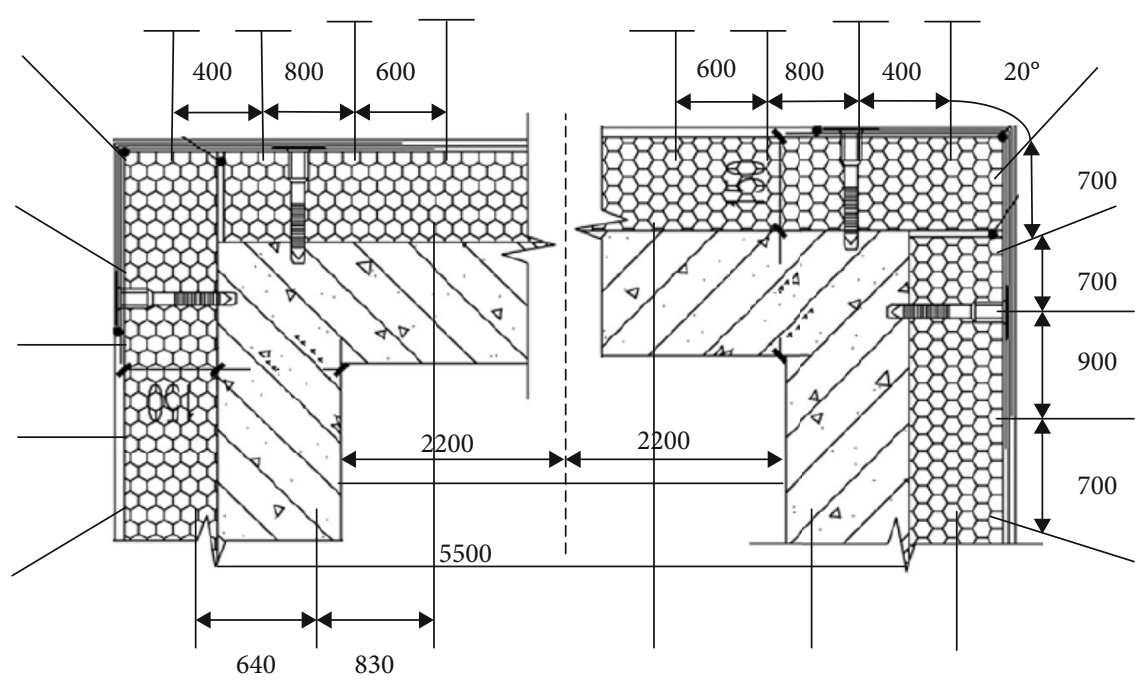

FIgURE 4: Support plan after optimization of the upper seam roadway.

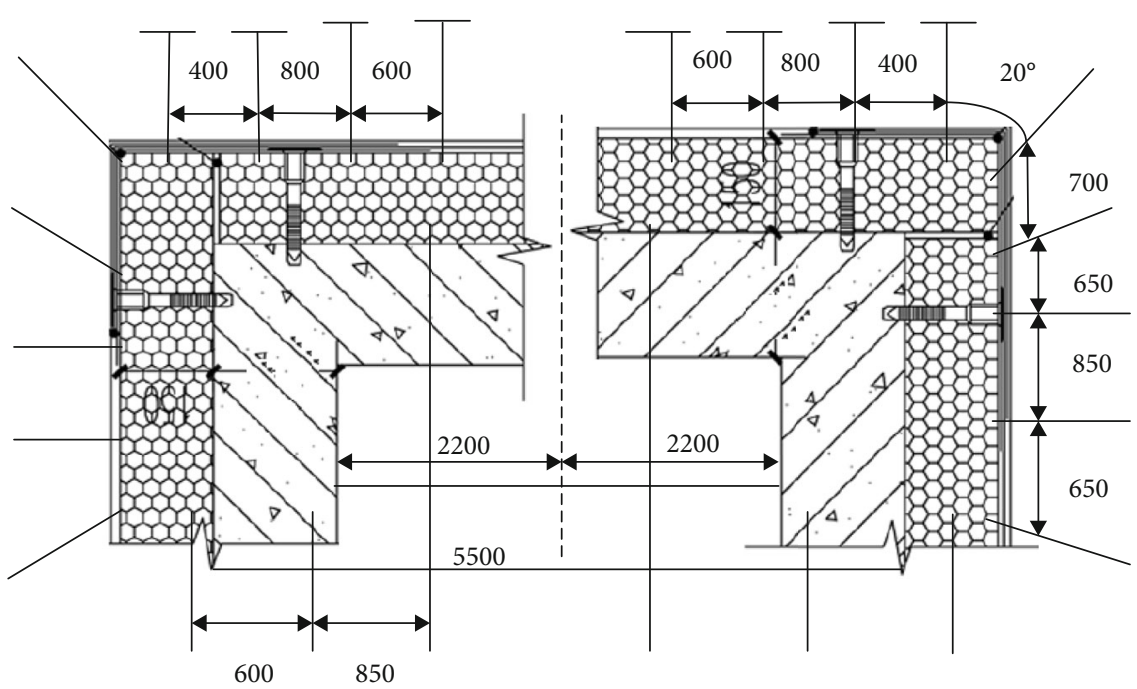

FIGURE 5: Support plan after optimization of the lower coal seam roadway.

The optimized support plan of the lower coal seam roadway is shown in Figure 5.

\subsection{On-Site Monitoring}

3.3.1. Monitoring Purpose. Due to the complex and diverse geological conditions of coal mine projects, it is difficult to accurately grasp the surrounding rock deformation and support structure deformation caused by excavation in the construction process, which brings great safety risks to the coal mine construction [26]. Therefore, coal mine monitoring is an essential work in coal mine construction and an important measure to ensure construction safety. In the process of coal mine construction, it is necessary to strengthen the monitoring and measurement of surrounding rock deformation, real-time feedback of monitoring information, and timely processing and analysis of monitoring results, so as to ensure the smooth progress of coal mine work and ensure the safety of construction operation and on-site personnel [27]. follows:

The purpose of this engineering monitoring is shown as

(1) Timely grasp the deformation law of surrounding rock and support structure during coal mine excavation, and provide data support for field operations, which can quickly and effectively deal with the occurrence of abnormal surrounding rock in the tunnel during excavation and ensure the safety of construction $[28,29]$

(2) The monitoring of the support structure can enable the construction personnel to deeply understand the role and effect of the support structure, so as to determine a more reasonable and effective support plan 
TABLE 1: Contents of required test items.

\begin{tabular}{|c|c|c|c|}
\hline $\begin{array}{l}\text { Serial } \\
\text { number }\end{array}$ & Work content & Measuring instrument & $\begin{array}{l}\text { Measurement } \\
\text { accuracy }\end{array}$ \\
\hline 1 & $\begin{array}{l}\text { Observation inside and outside the } \\
\text { cave }\end{array}$ & Field observation & \\
\hline 2 & Vault sinking measurement & $\begin{array}{l}\text { Electronic level, steel hanging ruler, indium steel ruler, total } \\
\text { station }\end{array}$ & $0.01 \mathrm{~mm}$ \\
\hline 3 & $\begin{array}{l}\text { Peripheral displacement } \\
\text { measurement }\end{array}$ & Convergence meter, total station & $0.01 \mathrm{~mm}$ \\
\hline 4 & Ground settlement measurement & Electronic level, indium steel ruler, total station & $0.01 \mathrm{~mm}$ \\
\hline
\end{tabular}

(3) By analyzing the daily monitoring data, the field personnel can find the problems as soon as possible, communicate with the designer, and make design changes in time, so that the design plan is more in line with the actual situation of the site

\subsubsection{Monitoring Content and Plan}

(1) Required Items of Monitoring Measurement Are Shown in Table 1.

(2) Layout of Monitoring Points. The deformation and stress change of surrounding rock of coal mine can be grasped in time by arch settlement monitoring, and the stability of coal mine can be determined effectively. Measuring point layout: an anchor pile is set at the measuring point of the mining wool hole. The depth of the measuring point is $30 \mathrm{~mm}$, and the diameter of the drilling hole is $22 \mathrm{~mm}$. It is fixed with fast setting cement or early-strength anchoring agent, and an angle iron is fixed at the measuring pile head.

The remote measurement of the settlement of the vault and the surrounding measurement and monitoring section is shown in Table 2 .

In addition, the reading of initial deformation value should be completed before the next cycle of excavation.

(3) Measuring Frequency. According to the observation frequency of arch settlement and peripheral convergence, it is determined according to the deformation rate and the distance from the dug surface, as shown in Tables 3 and Table 4, respectively.

The measurement frequency determined by the rate of convergence and the distance from the excavation face is in principle high frequency.

(4) Measurement Method. The arch vault subsidence measurement method uses the total station plus reflector to measure the coordinates of the measurement points, and the measured elevation difference value is the settlement amount [30-38].

In the peripheral convergence measurement method, the total station and reflector are used for measurement. The coordinates of the measuring points are measured by
TABle 2: Principles for selecting monitoring surfaces.

\begin{tabular}{lc}
\hline Surrounding rock level & Section spacing \\
\hline II & According to the specific situation \\
III & $30 \sim 50 \mathrm{~m}$ \\
IV & $10 \sim 30 \mathrm{~m}$ \\
V & $5 \sim 10 \mathrm{~m}$ \\
\hline
\end{tabular}

TABLE 3: Measuring frequency of dome subsidence and peripheral convergence displacement (displacement according to velocity).

\begin{tabular}{lc}
\hline Displacement speed $(\mathrm{mm} / \mathrm{d})$ & Measuring frequency \\
\hline$\geq 5$ & $2 \sim 3$ times $/ \mathrm{d}$ \\
$1 \sim 5$ & 1 time $/ \mathrm{d}$ \\
$0.5 \sim 1.0$ & 1 time $/ 2 \sim 3 \mathrm{~d}$ \\
$0.2 \sim 0.5$ & 1 time $/ 3 \mathrm{~d}$ \\
$<0.2$ & 1 time $/ 3 \sim 7 \mathrm{~d}$ \\
\hline
\end{tabular}

TABle 4: Measurement frequency of dome subsidence and peripheral convergence displacement (according to the distance from the excavation surface).

\begin{tabular}{lc}
\hline $\begin{array}{l}\text { Distance between measuring section and } \\
\text { working surface }(\mathrm{m})\end{array}$ & $\begin{array}{c}\text { Measuring } \\
\text { frequency }\end{array}$ \\
\hline$(0 \sim 1) \mathrm{B}$ & 2 times $/ \mathrm{d}$ \\
$(1 \sim 2) \mathrm{B}$ & $1 \mathrm{time} / \mathrm{d}$ \\
$(2 \sim 5) \mathrm{B}$ & $1 \mathrm{time} / 2 \sim 3 \mathrm{~d}$ \\
$>5 \mathrm{~B}$ & $1 \mathrm{time} / 3 \sim 7 \mathrm{~d}$ \\
\hline
\end{tabular}

cross-sectional measurement at the rear of the total station, and the distance between the measuring points is calculated according to the coordinates. The distance difference between the two measurements is the convergence.

3.3.3. Analysis of Monitoring Results. Three sections of the right line opening section are selected to carry out monitoring measurement and data analysis for the settlement of the arch roof and horizontal convergence of the side wall. The data curves of the three sections within 70 observation days are shown in Figure 6.

As shown in Figures 6, 10 days before coal mine excavation, the settlement and horizontal convergence of the section arch roof increase rapidly. With the increase in 


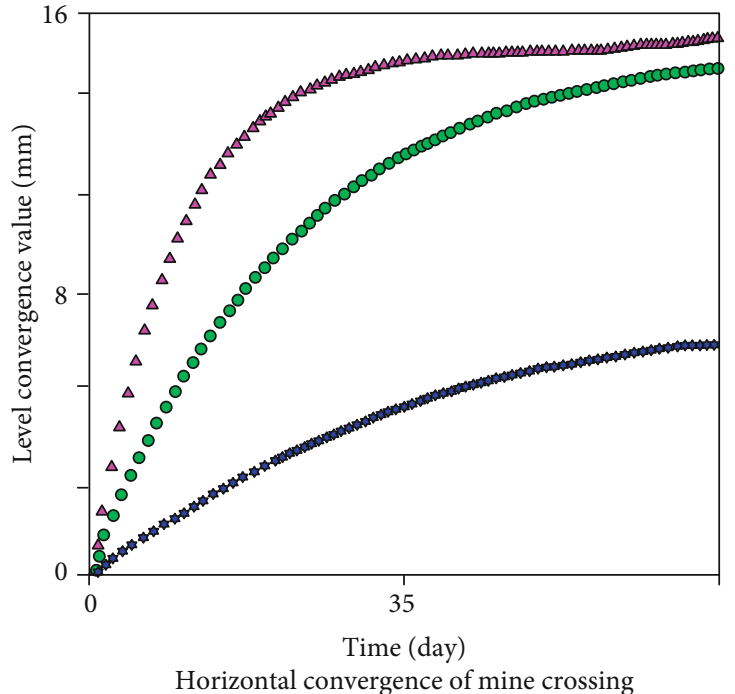

$\triangle \mathrm{N} 3$

O N2

N1

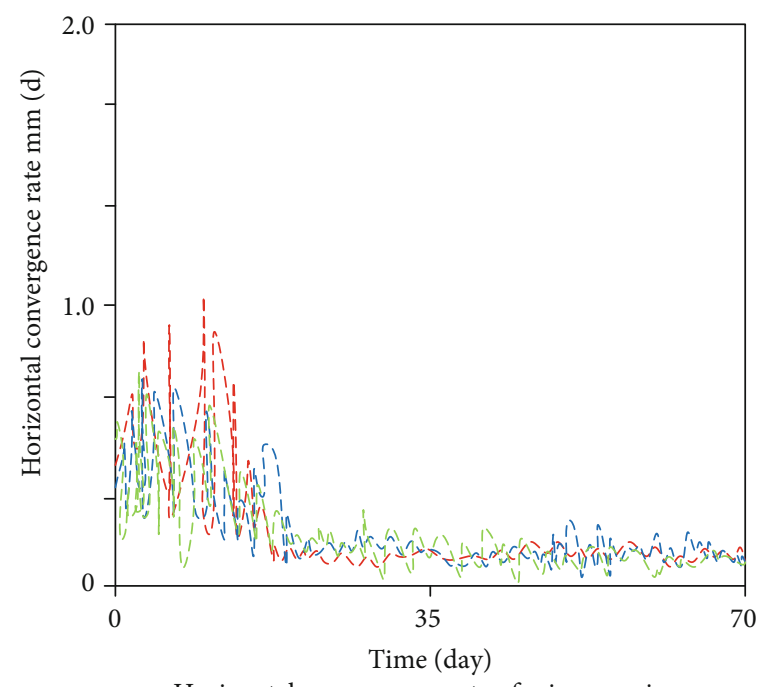

Horizontal convergence rate of mine crossing

$---\mathrm{N} 3$

$---\mathrm{N} 2$

$---\mathrm{N} 1$
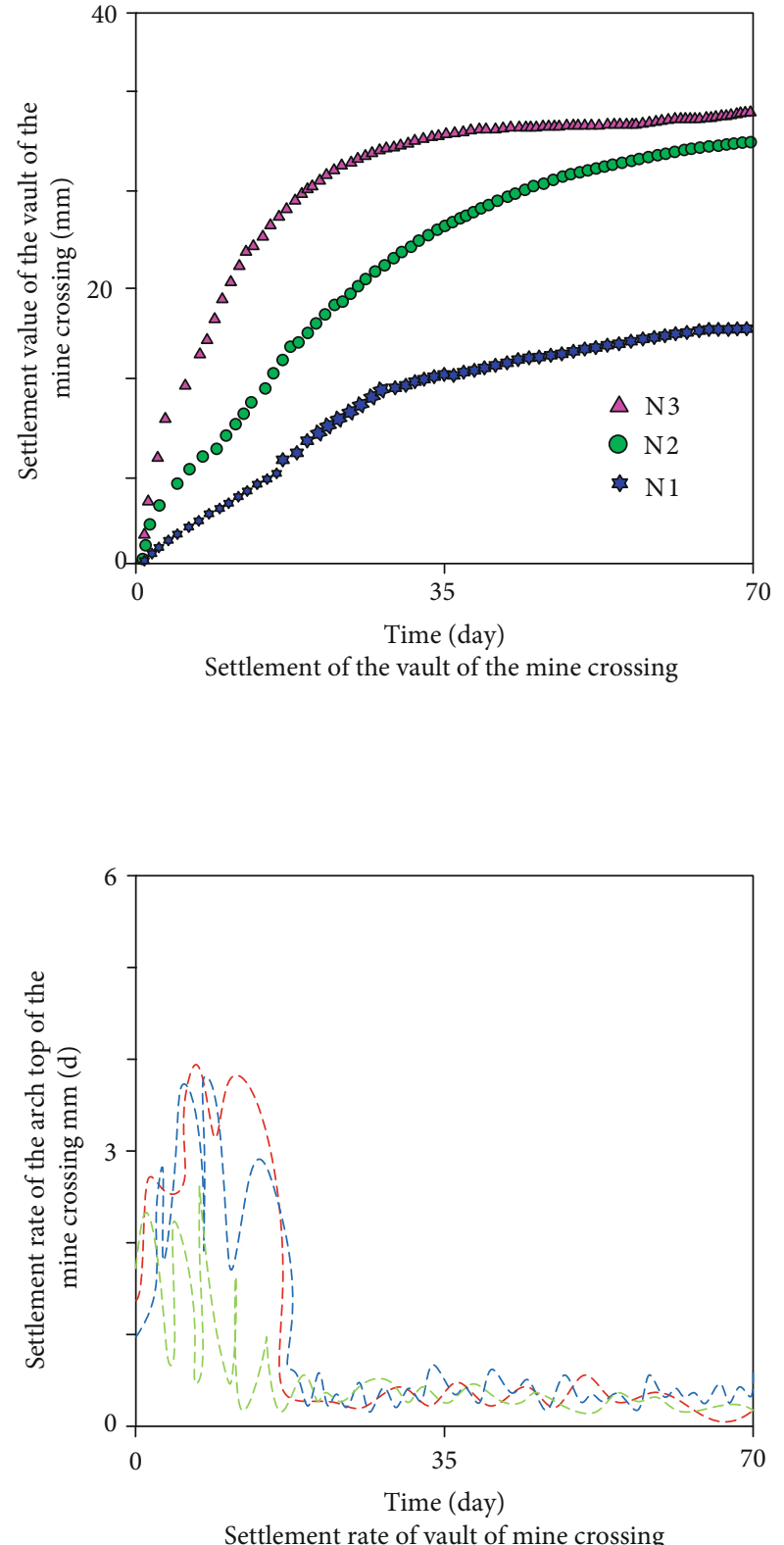

Settlement rate of vault of mine crossing

FIGURE 6: Data curve of the coal mine opening section.

excavation time, the settlement and horizontal convergence of the section arch roof continue to increase, but the growth rate gradually decreases. After about 60 days, the settlement of the vault tends to be stable; after about 60 days, the horizontal convergence of $\mathrm{N} 1$ and $\mathrm{N} 2$ tends to be stable; and after about 50 days, the horizontal convergence of N3 tends to be stable. With the increase in excavation depth and section burial depth, the cumulative settlement value and horizontal convergence value of the arch roof gradually decrease, the surrounding rock stability is high, and the support structure plays a role. It can be seen that coal mine surrounding rock deformation can be divided into three stages on the whole:
(1) The initial surrounding rock deformation is rapid, and the deformation rate is very high. In just 10 days, the maximum settlement rate of the $\mathrm{N} 1$ section reaches $4.7 \mathrm{~mm} / \mathrm{d}$, the settlement of vault reaches $24.9 \mathrm{~mm}$, accounting for $65.4 \%$ of the total settlement, and the horizontal convergence reaches $10.92 \mathrm{~mm}$, accounting for $71.4 \%$ of the total convergence. The maximum settlement rate of the $\mathrm{N} 2$ section reaches $5.6 \mathrm{~mm} / \mathrm{d}$, the settlement amount of vault reaches $26.43 \mathrm{~mm}$, accounting for $74.1 \%$ of the total settlement amount, and the horizontal convergence amount reaches $10.03 \mathrm{~mm}$, accounting for $67.3 \%$ of the total settlement amount. Within 15 
days of excavation, the maximum settlement rate of section $\mathrm{N} 3$ reaches $2.7 \mathrm{~mm} / \mathrm{d}$, the settlement amount of vault reaches $15.79 \mathrm{~mm}$, accounting for $64.2 \%$ of the total settlement amount, and the horizontal convergence amount reaches $6.53 \mathrm{~mm}$, accounting for $62.0 \%$ of the total convergence amount. This is because the surrounding rock of the entrance of the coal mine is not stable enough, the construction has great disturbance to it, and the supporting structure has not played an effective supporting role

(2) After 10 to 15 days of excavation, the deformation rate of surrounding rock decreases and the amount of deformation increases slowly. Within about 45 days, the maximum settlement rate of section $\mathrm{N} 1$ is $0.41 \mathrm{~mm} / \mathrm{d}$, the increase in settlement is $13.2 \mathrm{~mm}$, accounting for $35.0 \%$ of the total settlement, and the increase in horizontal convergence is $5.03 \mathrm{~mm}$, accounting for about $32.9 \%$. The maximum settlement rate of section $\mathrm{N} 2$ is $0.55 \mathrm{~mm} / \mathrm{d}$, the increase in settlement is $9.27 \mathrm{~mm}$, accounting for about $26.0 \%$, and the increase in horizontal convergence is $4.87 \mathrm{~mm}$, accounting for about $32.7 \%$. The maximum settlement rate of section $\mathrm{N} 3$ is $0.52 \mathrm{~mm} / \mathrm{d}$, the increase in settlement is $8.81 \mathrm{~mm}$, accounting for about $35.8 \%$, and the increase in horizontal convergence is $4.01 \mathrm{~mm}$, accounting for about $38.1 \%$. It can be seen that the surrounding rock is still in deformation at this stage, but the speed is slow and the increment is small. This is because the supporting structure in the cave plays its own role at this time, and the surrounding rock stress is redistributed

(3) After the deformation relaxation period, the deformation rate tends to be zero, the settlement of the $\mathrm{N} 1$ arch crown reaches $38.1 \mathrm{~mm}$, and the horizontal convergence amount reaches $15.3 \mathrm{~mm}$; the settlement of section $\mathrm{N} 2$ vault reaches $35.7 \mathrm{~mm}$, and the horizontal convergence amount reaches $14.9 \mathrm{~mm}$; the settlement of section $\mathrm{N} 3$ vault reaches $24.6 \mathrm{~mm}$, and the horizontal convergence amount reaches $10.54 \mathrm{~mm}$. At this stage, the deformation of the three sections is basically unchanged, and the surrounding rock is in a stable state on the whole

According to the above analysis, the deformation of surrounding rock of coal mine changes dynamically with the excavation time, which can be divided into three deformation stages: (1) the early rapid deformation stage, (2) the middle slow deformation stage, and (3) the late basic stability stage.

3.4. Comparison between Numerical Simulation Results and Monitoring Results. In order to verify the rationality of the numerical simulation, this paper compares the finite element simulation results of vault settlement and horizontal convergence with the field measured values. The comparison results are shown in Table 5 .

It can be seen from Table 5 that the numerical simulation results of vault subsidence and horizontal convergence
TABLE 5: Comparison of calculated and measured values (unit: $\mathrm{mm})$.

\begin{tabular}{|c|c|c|c|}
\hline $\begin{array}{l}\text { Fault } \\
\text { plane }\end{array}$ & $\begin{array}{l}\text { Comparison } \\
\text { item }\end{array}$ & $\begin{array}{c}\text { Vault } \\
\text { settlement }\end{array}$ & $\begin{array}{l}\text { Horizontal } \\
\text { convergence }\end{array}$ \\
\hline \multirow{3}{*}{ N1 } & Calculated & 44.16 & 11.45 \\
\hline & $\begin{array}{l}\text { Monitoring } \\
\text { value }\end{array}$ & 37.72 & 10.05 \\
\hline & Relative error & $14.58 \%$ & $12.23 \%$ \\
\hline \multirow{3}{*}{ N2 } & Calculated & 45.19 & 12.89 \\
\hline & $\begin{array}{l}\text { Monitoring } \\
\text { value }\end{array}$ & 42.65 & 11.64 \\
\hline & Relative error & $5.62 \%$ & $9.70 \%$ \\
\hline \multirow{3}{*}{ N3 } & Calculated & 46.69 & 13.49 \\
\hline & $\begin{array}{l}\text { Monitoring } \\
\text { value }\end{array}$ & 40.67 & 13.01 \\
\hline & Relative error & $12.89 \%$ & $3.56 \%$ \\
\hline
\end{tabular}

of the three monitored sections are close to the field monitoring values, and the error is less than $15 \%$, which indicates that the numerical simulation results are reasonable. Due to field construction and measurement methods, the simulated calculated value is larger than the measured value, and the deformation of surrounding rock is mainly generated after excavation, so part of the deformation at the initial excavation stage cannot be measured.

\section{Conclusion}

In order to solve the engineering problems caused by the deformation of the upper and lower roadways in the process of mining and driving near the mine mouth, based on the elastic theory, this paper establishes the mechanical analysis model of the upper coal seam roadway under the action of the abutment pressure. By calculating the stress of any unit rock mass in the roadway side and based on the stress diffusion principle of soil mechanics theory, the surrounding rock deformation of the roadway in the lower coal seam is carried out. Through the establishment of the stress diffusion model under the abutment pressure of the coal pillar of the inner staggered upper coal seam roadway in the close distance coal seam, the lower coal seam is determined to be outside the stress influence range of the upper coal seam left coal pillar floor, and the calculation equation of the upper and lower roadway safety offset is given, which greatly reduces the difficulty of roadway maintenance in the later stage.

\section{Data Availability}

The data used to support the findings of this study are included within the article.

\section{Conflicts of Interest}

The authors declare no conflict of interest. 


\section{Acknowledgments}

This work is partially supported by Key Scientific Research Projects of Universities in Henan Province (21A440015).

\section{References}

[1] D. R. H. Jones and M. F. Ashby, "Creep and creep fracture," Engineering Materials 1, vol. 1, 2019.

[2] H. Altenbach, "Fundamentals of continuum mechanics - classical approaches and new trends," J Phys: Conf Ser, vol. 991, article 012003, 2018.

[3] S. Aziznejad, K. Esmaieli, and J. Hadjigeorgiou, "Responses of jointed rock masses subjected to impact loading," Journal of Rock Mechanics and Geotechnical Engineering, vol. 10, no. 4, pp. 624-634, 2018.

[4] Nguyen and H. T. Tai, "Modelling the mechanical behaviour of asphalt concrete using the Perzyna viscoplastic theory and Drucker-Prager yield surface," Speculum vitae humanae, vol. 18, no. sup2, pp. 264-280, 2017.

[5] B. Wassermann, S. Kollmannsberger, and S. Yin, "Integrating $\mathrm{CAD}$ and numerical analysis: 'dirty geometry' handling using the finite cell method," Computer Methods in Applied Mechanics and Engineering, vol. 351, pp. 808-835, 2019.

[6] L. W. Liu and H. K. Hong, "Clifford algebra valued boundary integral equations for three-dimensional elasticity," Applied Mathematical Modelling, vol. 54, pp. 246-267, 2018.

[7] D. Lukáš, O. F. Gunther, and J. Zapletal, “A boundary element method for homogenization of periodic structures," Mathematical Methods in the Applied Sciences, vol. 43, no. 3, pp. 1035-1052, 2020.

[8] J. C. Lachat and J. O. Watson, "Effective numerical treatment of boundary integral equations: a formulation for threedimensional elastostatics," International Journal for Numerical Methods in Engineering, vol. 10, no. 5, pp. 991-1005, 2010.

[9] C. N. Van, "Numerical investigation of circle defining curve for two-dimensional problem with general boundaries using the scaled boundary finite element method," Frontiers of Structural and Civil Engineering, vol. 92, 102 pages, 2019.

[10] A. Lisjak, Q. Liu, and Q. Zhao, "Numerical simulation of acoustic emission in brittle rocks by two-dimensional finitediscrete element analysis," Geophysical Journal International, vol. 195, no. 1, pp. 423-443, 2013.

[11] H. S. Kazemi and S. M. Tavakkoli, "ON the performance of isogeometric analysis for elasto-plastic plane stress problems," Asian Journal of Civil Engineering, vol. 19, no. 1, pp. 55-65, 2018.

[12] Q. Xu, P. Cheng, P. Su, J. Dong, and G. Chen, "Study on the mechanical characteristics of shallow-buried unsymmetrical pressure tunnel entry construction," Chinese Journal of Underground Space and Engineering, vol. 13, no. 5, pp. 1311-1318, 2017.

[13] Y. Liang, "Study on the construction mechanics characteristics and control technology of the opening section of shallowburied unsymmetrical pressure tunnel," China Highway, vol. 21, pp. 116-117, 2017.

[14] Z. Xu, "The application of the combined support technology of pile foundation guide wall and long pipe roof in the construction of soft surrounding rock tunnel," Construction Technology, vol. 46, no. S 1, pp. 729-732, 2017.
[15] Z. Song, T. Wang, J. Zhou, and W. Yu, "Construction optimization and stress characteristics analysis of shallow buried large cross-section tunnels," Chinese Journal of Underground Space and Engineering, vol. 13, no. 2, pp. 459-468, 2017.

[16] H. Dong, "Research on the layout of coal mining roadways at very close distances," Coal Technology, vol. 35 , no. 4, pp. 5052, 2016.

[17] Y. Yang, "Research on the reasonable location of the shortdistance coal mining roadway under the coal pillar," Modernization of Coal Mines, vol. 3, pp. 19-22+25, 2018.

[18] W. Wang, "Layout optimization of short-distance coal seams under the goaf," Modernization of Coal Mines, vol. 6, pp. 13, 2018.

[19] F. Yong, "Research on the reasonable layout of dynamic pressure mining roadway under the short-distance coal seam goaf," Coal Technology, vol. 39, no. 4, pp. 6-9, 2020.

[20] X. Qu, F. Jiang, H. Wang et al., "Research on the mechanism of coal seam impact induced by coal pillar instability in goaf," Journal of Mining and Safety Engineering, vol. 34, no. 6, pp. 1134-1140, 2017.

[21] Z. Hua, C. Zhiwei, and Z. Xue, "Numerical analysis and support design of surrounding rock deformation of low-level coal seam roadway at close range," Shenhua Science and Technology, vol. 16, no. 11, pp. 42-46, 2018.

[22] F. Xiaofei, "Research on the deformation and failure law of coal roadway surrounding rock under the influence of fully mechanized caving mining," Shanxi Coking Coal Science and Technology, vol. 43, no. 9, pp. 49-52, 2019.

[23] Z. Li, D. Liu, X. Liu, D. Yuan, L. Du, and X. Xiao, "Research on the surrounding rock control of the mining roadway near the coal seam in a mine," Modern Mining, vol. 35, no. 3, pp. 7880+92, 2019.

[24] Z. Buyuan, "Research and application of surrounding rock control technology for mining roadways in short distance coal seam goaf," Modernization of Coal Mines, vol. 5, pp. 1-3, 2019.

[25] M. Guo, G. Peilin, and L. Peng, "Research on reinforcement and support parameters of roadway under goaf in extremely close coal seams," Coal Engineering, vol. 52, no. 1, pp. 54-58, 2020.

[26] J. Liu, Z. Yu, S. Liu, G. Jing, and H. Liu, "Study on the stability and reasonable offset of surrounding rock in combined mining of thin coal seams at close range," Coal Technology, vol. 36, no. 3, pp. 49-51, 2017.

[27] S. Hao and C. Wenhua, "Research on reasonable distance between coal mining faces in extremely short distance coal seams," China Work Safety Science and Technology, vol. 14, no. 4, pp. 51-56, 2018.

[28] L. Jianguang, "Research on the safety staggered distance of joint mining in close coal seam face," Contemporary Research in Chemical Industry, vol. 14, pp. 37-38, 2019.

[29] Y. Dong, "Asymmetric deformation and failure characteristics and control technology of the surrounding rock of the tunnel under the short-distance mined-out area," Coal Engineering, vol. 51, no. 4, pp. 26-29, 2019.

[30] M. Qingni, "Research on roadway support of lower working face in short-distance coal seam goaf," Coal Engineering, vol. 52, no. 5, pp. 63-66, 2020.

[31] Y. G. Zhang, J. Tang, R. P. Liao et al., "Application of an enhanced BP neural network model with water cycle algorithm on landslide prediction," Stochastic Environmental 
Research and Risk Assessment, vol. 35, no. 6, pp. 1273-1291, 2021.

[32] Y. G. Zhang, J. Tang, Z. Y. He, J. K. Tan, and C. Li, “A novel displacement prediction method using gated recurrent unit model with time series analysis in the Erdaohe landslide," Natural Hazards, vol. 105, no. 1, pp. 783-813, 2021.

[33] Y. G. Zhang and L. N. Yang, "A novel dynamic predictive method of water inrush from coal floor based on gated recurrent unit model," Natural Hazards, vol. 105, no. 2, pp. 20272043, 2021.

[34] Y. G. Zhang, Z. Zhang, and S. Xue, "Stability analysis of a typical landslide mass in the Three Gorges Reservoir under varying reservoir water levels," Environmental Earth Sciences, vol. 79 , no. 1,2020

[35] Y. G. Zhang, S. Y. Zhu, J. K. Tan, L. D. Li, and X. J. Yin, “The influence of water level fluctuation on the stability of landslide in the Three Gorges Reservoir," Arabian Journal of Geosciences, vol. 13, no. 17, p. 845, 2020.

[36] Y. G. Zhang, Y. Zhu, W. Q. Zhang, and H. Liu, "Analysis of deformation characteristics and stability mechanisms of typical landslide mass based on the field monitoring in the Three Gorges Reservoir, China," Journal of Earth System Science, vol. 1, 2019.

[37] B. Gong, Y. J. Jiang, P. Yan, and S. Zhang, "Discrete element numerical simulation of mechanical properties of methane hydrate-bearing specimen considering deposit angles," Journal of Natural Gas Science and Engineering, vol. 76, p. 103182, 2020.

[38] B. Gong, Y. J. Jiang, and L. J. Chen, "Feasibility investigation of the mechanical behavior of methane hydrate- bearing specimens using the multiple failure method," Journal of Natural Gas Science and Engineering, vol. 69, p. 102915, 2019. 